\title{
EXPERIMENTAL STUDY OF RC EXTERIOR BEAM-COLUMN JOINT SUBJECTED TO TORSIONAL MOMENT
}

\author{
Tarek El-Shafiey ${ }^{1}$, Ahmed Atta $^{2}$, Hamdy Afefy $^{3}$, Mohamed Ellithy ${ }^{4}$ \\ ${ }^{1}$ Structural Engineering Department, Tanta University, Tanta, Egypt. \\ E-mail: telacrat1@yahoo.com \\ ${ }^{2}$ Structural Engineering Department, Tanta University, Tanta, Egypt. \\ E-mail: drahmedatta2003@yahoo.com \\ ${ }^{3}$ Structural Engineering Department, Tanta University, Tanta, Egypt. \\ E-mail: hamdyafefy@hotmail.com \\ ${ }^{4}$ Structural Engineering Department, Tanta University, Tanta, Egypt. \\ E-mail: mohamed.ellithy73@yahoo.com
}

\begin{abstract}
This paper presents the results of an experimental program conducted in order to investigate the behavior of Type-I beam-column Joints, where the beam was subjected to shear stresses due to combined effect of shear force and torsional moment (beam eccentric loading). Four beam-column joint specimens were constructed and tested up to failure in order to better understand the complicated behaviour due to combined loading transmitted from the beam to the column. The studied parameters were the configuration of beam side and secondary reinforcement and the existence of the joint reinforcing stirrups. Generally, the shear failure at the beam zone or at the joint panel was noticed to be the governing mode of failure for all tested specimens. The test results shed the light on the importance of longitudinal side reinforcing steel configuration, the inadequate embedded length of the beam side and secondary steel into the joint panel including stirrups led to decrease the beam capacity but it kept the failure away from the joint panel.
\end{abstract}

Keywords: Beam-column joint, combined loading, failure, shear, torsion, reinforcement configuration.

\section{Introduction}

A beam-column joint is defined as that portion of the column within the depth of beam that frames into the column at which the axial load and the shear forces transmitted through (ACI 352R-2). One of the most important systems resisting lateral loads is the framed system, thus the importance of the connections between the beams and the columns have been revealed. The previous researches presented several failure modes which took place on the beamcolumn joints and can be summarized to four main modes of failure; joint shear failure, slippage of the beam main steel, yielding of the beam main steel (beam hinging) and yielding of the column main steel (column hinging). Shear and bond failure in the joints can be classified as a brittle failures so that for safety requirements, these types of failures should be eliminated in order to avoid the catastrophic results. Shear failure of beam-column joints is considered as the principal cause of collapse for many moment-resisting frame buildings during recent earthquakes. Inadequate transverse reinforcement in the joint panel and weakcolumn/strong-beam design are the main reasons for the observed joint shear failures during recent earthquakes. Previous research work focused on studying the shear strength of the beam-column joint and the corresponding key parameters such as the existence of joint stirrups and the beam longitudinal steel configuration. The exterior beam-column joints (EBC) in reinforced concrete structures built according to old practice were observed to be underperformed during earthquakes. This is due to the lack of shear reinforcement and 
improper construction practice. In addition, it was found that the anchorage configuration has a significant influence on the load carrying capacity and failure mode of EBC joints. Shear failure of joint core and slippage of flexural reinforcement are found to be the modes of failure in substandard EBC joints. While the EBC joints designed according to ACI 318-83 and old Japanese practice (AIJ 1988) failed due to the lack of shear reinforcement, the EBC joints designed according to old Indian practice (IS 13920 1993) failed due to slippage of flexural reinforcement in addition to joint shear failure. Among the substandard EBC joints considered in the study, the joint designed according to ACI 318-83 is observed to have better performance when compared to the other anchor-age configurations (Kiran and Genesio 2014). Researchers took into consideration the effect of stirrups at joint zone. The gravitydesigned RC fram/es with the joint as the weakest component were subjected to lateral actions, they experienced severe damage in the joint panels and ultimately suffer joint shear failure before the formation of a plastic hinge in the adjoining members (Dhakal et al. 2005). Horizontal stirrups in the beam-column joints with non-seismic design can effectively improve the seismic behavior and enhance the joint shear strength. It is recommended that the upper limit of the horizontal stirrup ratio in non-seismically designed exterior beam-column joints under low-to moderate seismicity for enhancing the shear capacity to be $0.4 \%$, additional transverse reinforcement provided to the joint may have less effect on the joint shear strength enhancement (Kaung and Wong 2011). The steel detailing was also considered in the previous work, thus column crossed inclined bars was a feasible solution to increase the joint shear capacity for the cyclically loaded beam-column joints. The presence of inclined bars introduces an additional mechanism of shear transfer. The greater the joint aspect ratio $(\mathrm{hb} / \mathrm{hc})$ the lesser the contribution of the crossed inclined bars to the joint shear capacity (Kularni and Patil 2013). Another trend of previous research work was studying the additional shear stresses through the joint panel owing to the torsional moment generated by the eccentricity of the beam axis to the column axis. The beams internal and external forces transfer through joint to the column away from its centroidal axis so that a torsional moment generates along the column height. Moreover, brittle shear failures of eccentric joints subjected to additional shear forces were observed from the previous earthquake damages. Analysis of building damages during earthquakes has proven that the torsional moment due to eccentric beam-column joints has greatly reduced the shear capacity of the column (Zhou et al. 1998). Inspections and analysis of the seismic damage have proven that some damages can be attributed to excessive torsional moment due to eccentric beam-column joint. Hence the additional stresses due to torsional moment of the eccentric beam-column joints should be taken into account in structural design and in seismic diagnosis (Zhou et al. 2000). The calculation of joint shear strength using the joint effective width prescribed in the AIJ standard underestimated the experimental results. The degree of underestimation depends on the eccentric distance (Goto and Joh 2004). The majority of previous researches focused on the structural performance of reinforced concrete moment-resisting frames which located at regular buildings, ignoring the effect of irregularity of building and the resulting twisting movements generated on plane of the floors. These twisting movements resulted in a complicated case of loading for the RC elements of the moment-resisting frame which include biaxial moment, torsional moment and normal force acting on each element of the RC frame (Thanoon 2004).

\section{Research Significance}

According to ACI 352R-2, additional research is needed on the behaviour of the beamcolumn joints particularly under torsion. Accordingly, as the aim of further understanding of the overall structural performance of the beam-column joints subjected to this complicated case of loading, this paper introduced an experimental study consisted of four beam-column joint specimens. The experimental study shed 
the light on the transferred torsional moment from the beam to the joint panel under static loading.

\section{Experimental Program}

\subsection{Specimen details}

The experimental program consisted of four reinforced concrete exterior beam-column joint specimens. The specimens were designed according to the Egyptian code of practice (ECP 203-2007). The calculated $\mathrm{SM}_{\mathrm{c}} / \mathrm{SM}_{\mathrm{b}}$ for the tested specimens equals to 1.20 which satisfy the concept of weak-girder strong-column. All specimens' columns had the same cross sectional area of $180 \mathrm{~mm}$ depth and $500 \mathrm{~mm}$ width and all beams had the same depth of $400 \mathrm{~mm}$ and the same width of $200 \mathrm{~mm}$. The columns were provided by the same uniformly distributed longitudinal reinforcement of 12D18 and the same transverse steel of D12@100 mm. All beams had the same longitudinal and transverse steel ratios. The embedded length of the beam main steel $(800 \mathrm{~mm}$ ) and the joint reinforcement (3D10) were calculated according to ECP 203-2007. The rigid arm used to generate the eccentric loading of the beam was designed not to be cracked until the failure of specimen. The typical concrete dimensions for all specimens are shown in Figure 1 and detailed in Table 1. In addition, reinforcement configurations for all specimens are depicted in Figure 2.

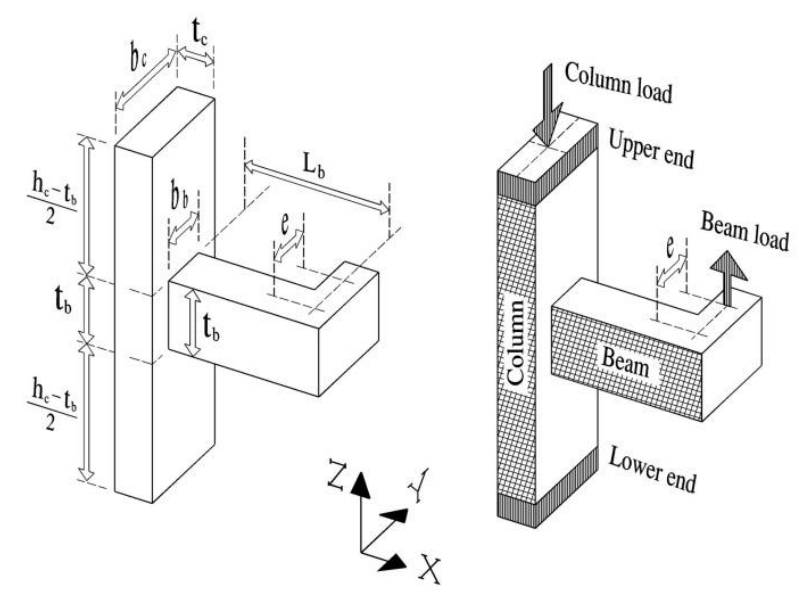

Figure 1. Typical concrete dimensions of the tested specimens.

\subsection{Material properties}

The used concrete patch was normal strength concrete (NSC) mixture designed using the available materials. The Mix proportions for concrete were $1295 \mathrm{~kg}$ per one cubic meter of crushed dolomite with maximum aggregate size of $10 \mathrm{~mm}, 637 \mathrm{~kg}$ of sand, $350 \mathrm{~kg}$ Portland cement and the water to cement ratio $(\mathrm{w} / \mathrm{c})$ of 0.50 . The specimens were poured altogether which resulted in average 28 -day concrete cylinder strength of $25.5 \mathrm{MPa}$. Tension tests were performed on the reinforcing steel by the universal testing machine on four typical $800 \mathrm{~mm}$ length specimens in order to obtain the yield and ultimate strengths. The average yield strength was $418.4 \mathrm{MPa}$, while the corresponding average ultimate tensile strength was 620.9MPa. 


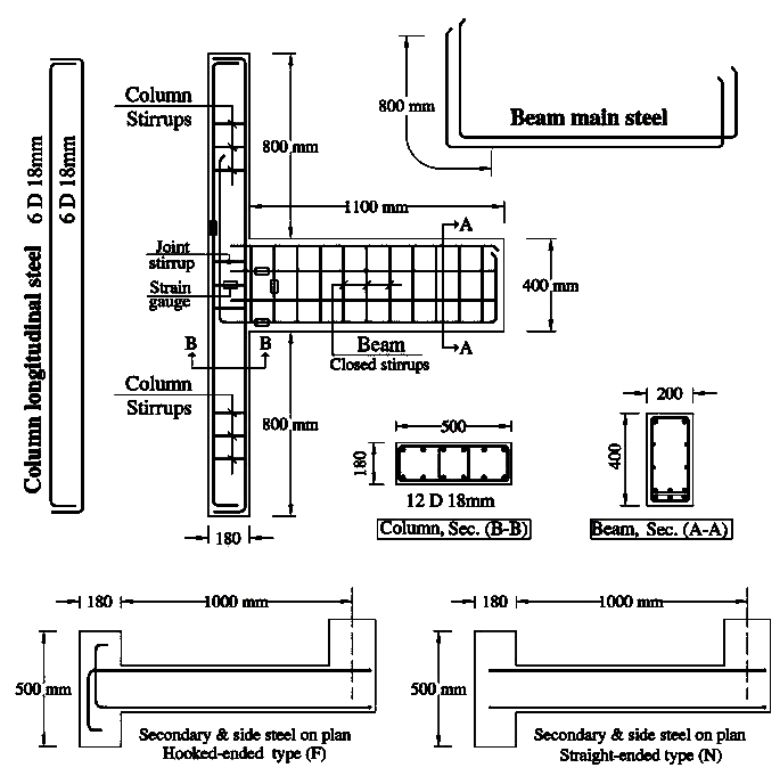

Figure 2. Reinforcement configurations for all tested specimens.

Table 1. Specimens dimensions and reinforcement.

\begin{tabular}{|c|c|c|c|c|c|c|c|c|c|c|c|c|c|c|c|}
\hline \multirow{2}{*}{ 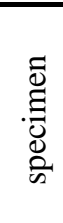 } & \multirow{2}{*}{$\begin{array}{c}\mathrm{e} \\
(\mathrm{mm})\end{array}$} & \multicolumn{3}{|c|}{$\begin{array}{c}\text { Beam } \\
\text { dimensions } \\
(\mathrm{mm})\end{array}$} & \multicolumn{3}{|c|}{$\begin{array}{c}\text { Column } \\
\text { dimensions } \\
(\mathrm{mm})\end{array}$} & \multicolumn{5}{|c|}{ Beam reinforcement } & \multicolumn{3}{|c|}{ Column reinforcement } \\
\hline & & $b_{b}$ & $t_{b}$ & $l_{b}$ & $b_{c}$ & $t_{c}$ & $\mathrm{~h}_{\mathrm{c}}$ & lower & upper & side & Stirrups & Type & Long. & stirrups & $\begin{array}{c}\text { Joint } \\
\text { stirrups }\end{array}$ \\
\hline SP1 & \multirow{4}{*}{ 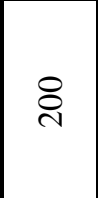 } & \multirow{4}{*}{ ৪) } & \multirow{4}{*}{$\underset{+}{\stackrel{f}{+}}$} & \multirow{4}{*}{8} & \multirow{4}{*}{8} & \multirow{4}{*}{ 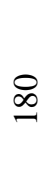 } & \multirow{4}{*}{ ঠి } & \multirow{4}{*}{$\frac{\infty}{6}$} & \multirow{4}{*}{$\frac{\infty}{\hat{\sim}}$} & \multirow{4}{*}{$\frac{v}{\theta}$} & \multirow{4}{*}{$\begin{array}{l}\text { D12@ } \\
100 \mathrm{~mm}\end{array}$} & $\mathrm{~N}$ & \multirow{4}{*}{$\stackrel{\infty}{\widehat{N}}$} & \multirow{4}{*}{$\begin{array}{l}\text { D12@ } \\
100 \mathrm{~mm}\end{array}$} & 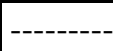 \\
\hline SP2 & & & & & & & & & & & & $\mathrm{N}$ & & & $3 \mathrm{D} 10$ \\
\hline SP3 & & & & & & & & & & & & $\mathrm{F}$ & & & |-------- \\
\hline SP4 & & & & & & & & & & & & $\mathrm{F}$ & & & $3 \mathrm{D} 10$ \\
\hline
\end{tabular}

e:The beam load eccentricity, $\mathbf{b} b$ : The width of the beam, $\mathbf{t}_{\mathbf{b}}$ : The total depth of the beam, $\mathbf{l} \mathbf{b}$ : The offset of the beam load from the column face, bc: The width of column, tc: The total depth of the column on the direction of loading, $\mathbf{h}_{\mathbf{c}}$ : The height of the column, $\mathbf{N}$ : The case of straight-ended side and secondary longitudinal steel of the beam, F: The case of hookedended side and secondary longitudinal steel of the beam, D: The diameter of steel bar. All symbols used at the previous table are also depicted in Figure1 and Figure2.

\subsection{Test setup and instrumentations}

One bay of three-dimensional steel frame was equipped and then used to carry out testing. The lower support of the columns was a steel cap and the upper support was a steel peg to prevent any tilting of the specimen during testing. $100 \mathrm{~mm}$ LVDTs were used in order to measure the vertical displacement at the tip of the beam and to measure the rotation of the beam section as shown in Figure 3. The pi-gauges with $100 \mathrm{~mm}$ gauge length also were used to facilitate determining the first crack propagation at the joint panel. Electrical resistance strain gauges with $10 \mathrm{~mm}$ gauge length were used to record the normal strain of beam main steel, beam stirrup strain, beam side steel strain, column longitudinal steel strain and joint stirrups strain as depicted in Figure 2 in order to determine the governing failure mode. A compression load equals to $400 \mathrm{kN}$, simulating the load in a real structure, was first applied to the column top end before the beam was loaded. Therefore, in several steps the beam was loaded up to failure. The loads on both column and beam were measured by a load cell of 600 
$\mathrm{kN}$ capacity. After each loading step, the vertical beam tip deflection, beam twisting angel and cracks propagation were recorded.

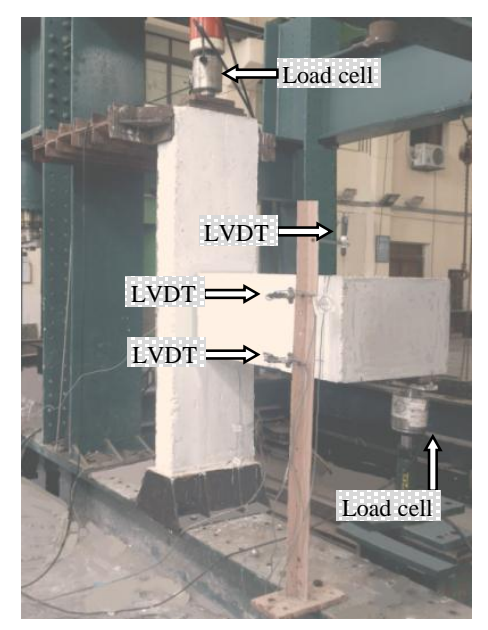

Figure 3. Test setup and instrumentations.

\section{Experimental Results and Discussion}

\subsection{Modes of failure}

It is obvious that shear stresses are resulted from the combined action of both the applied shear force $(\mathbf{n})$ and torsional moment $(\boldsymbol{\tau})$. The stresses orientations are not the same on the opposite sides of the beam, so that cracks propagated by a different way in the front and the back face of the beam. The tested specimens showed three main different failure modes according to the different parameters. Failure was detected according to the observed severe wide cracks on either beam sides or joint panel and the corresponding measured strains of the joint stirrups, beam stirrups, column main steel and beam main steel.

\subsubsection{Mode I: Beam failure due to shear force and torsional moment}

In this mode, the spalling of concrete cover was noticed to be occurred at the beams back face $(\mathbf{n}+\boldsymbol{\tau})$. Meanwhile, there were few cracks observed at the joint panel. The specimen failure took place at the beam zone by concrete crushing due to compressive principal stresses resulted out from shear force and torsional moment. The cracks inclination in the back and front faces indicates that the torsional moment contribution on failure is greater than that of shear force. This mode of failure was noticed for specimen SP2. Figure 4(a) shows the crack mapping of specimen SP2 showing Mode I of failure.

\subsubsection{Mode II: Shear failure at joint panel}

In this mode of failure, a major wide diagonal crack in the joint panel was observed due to absence of joint stirrups, as shown in Figure 4(b). Meanwhile, cracks widening was observed at the beams back face $(\mathbf{n}+\boldsymbol{\tau})$ but spalling of concrete cover did not take place and the cracks at the front face $(\mathbf{n}-\boldsymbol{\tau})$ was almost vertical indicating low shear stresses. It was obvious that the failure took place at joint panel due to shear stresses representing Mode II of failure. This mode of failure was noticed for specimens SP1 and SP3.

\subsubsection{Mode III: Shear failure at joint panel followed by beam deterioration due to torsional moment}

In this mode, the joint panel was severely damaged due to high loading level then widening of shear cracks took place at the beam of the specimen's back face $(\mathbf{n}+\boldsymbol{\tau})$ followed by the 
spalling of concrete cover. Thus, it was obvious that the specimen failure took place in both beam and joint panels due to shear stresses. This mode of failure was noticed for specimens SP4. Figure 4(c) shows the crack mapping of specimen SP4 showing Mode III of failure.

(a)

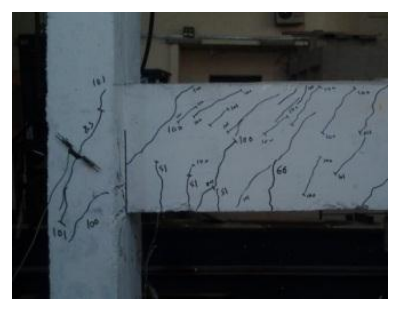

Front face $(\mathbf{n}-\boldsymbol{\tau})$

Figure 4(a). Crack mapping of specimen SP2, Mode I. (b) Back face $(\mathbf{n}+\boldsymbol{\tau})$

(c)

(d)

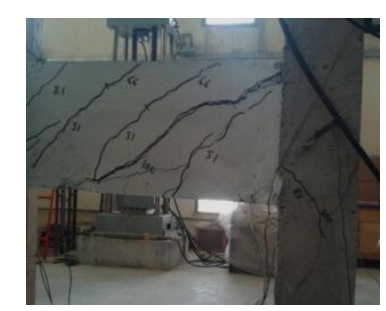

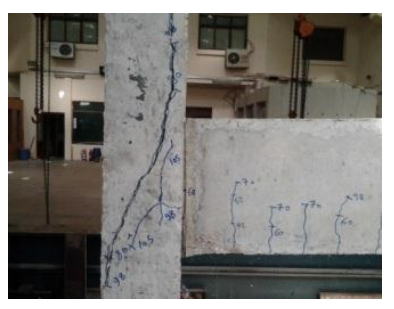

(b) Back face $(\mathbf{n}+\boldsymbol{\tau})$

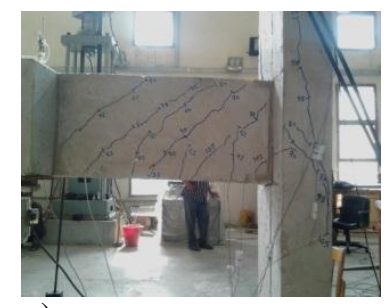

(a) Front face $(\mathbf{n}-\boldsymbol{\tau})$

Figure 4(b). Crack mapping of specimen SP3, Mode II.

$\begin{array}{ll}\text { (a) Front face }(\mathbf{n}-\boldsymbol{\tau}) & \text { (b) Back face }(\mathbf{n}+\boldsymbol{\tau})\end{array}$

Figure 4(c). Crack mapping of specimen SP4, Mode III.

\subsection{Cracking and failure loads}

The results of all tested specimens are summarized in Table 2, including the load at the initiation of the flexural-shear crack, the load at the initiation of the joint shear crack, the failure load, the beam tip deflection, the twist angel of the beam section at failure load and the dominant mode of failure. The flexural and diagonal cracking loads were determined from the direct observation of the crack patterns during testing. The data from Pi-gauges also used to determine the first crack propagation at joint panel. It was noticed that the specimens SP1, SP2, SP3 and SP4 experienced approximately the same cracking load due to the similarity of dimensions, material properties and the identical reinforcement ratios of the specimens which led to the same stiffness. All tested specimens showed approximately the same load at which the first crack propagated at the joint panel. 
Table 2. Test results

\begin{tabular}{|c|c|c|c|c|c|c|c|c|c|}
\hline \multirow{2}{*}{ 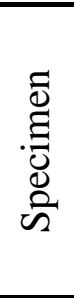 } & \multirow{2}{*}{$\begin{array}{l}\mathrm{f}_{\mathrm{c}}{ }^{\prime} \\
(\mathrm{MP} \\
\text { a) }\end{array}$} & \multicolumn{2}{|c|}{$\begin{array}{c}\text { Beam initial } \\
\text { cracking }\end{array}$} & \multirow{2}{*}{$\begin{array}{c}\text { Joint } \\
\text { crackin } \\
\mathrm{g} \\
\text { load } \\
(\mathrm{kN})\end{array}$} & \multirow{2}{*}{$\begin{array}{c}\text { Ultimat } \\
\text { e } \\
\text { Load } \\
(\mathrm{kN})\end{array}$} & \multirow{2}{*}{$\begin{array}{c}\text { Cracking } \\
\text { load to } \\
\text { failure } \\
\text { load } \\
\text { ratio } \\
\left(\mathrm{P}_{\mathrm{cr}} / \mathrm{P}_{\mathrm{u}}\right) \\
\end{array}$} & \multirow{2}{*}{$\begin{array}{l}\text { Beam } \\
\text { ultimate } \\
\text { deflecti } \\
\text { on } \\
(\mathrm{mm})\end{array}$} & \multirow{2}{*}{$\begin{array}{c}\text { Beam } \\
\text { ultimat } \\
\mathrm{e} \\
\text { twist } \\
\text { angel } \\
\text { (radian) }\end{array}$} & \multirow{2}{*}{$\begin{array}{l}\text { Mode } \\
\text { of } \\
\text { failure }\end{array}$} \\
\hline & & $\begin{array}{c}\mathrm{P}_{\mathrm{cr}} \\
(\mathrm{kN})\end{array}$ & $\begin{array}{l}\mathrm{M}_{\mathrm{tcr}}=\mathrm{P}_{\mathrm{cr}} \mathrm{x} \\
\mathrm{e}(\mathrm{kN} . \mathrm{m})\end{array}$ & & & & & & \\
\hline SP1 & 25.3 & 43.1 & 8.6 & 60.0 & 90.9 & 0.47 & 16.5 & 0.019 & $\begin{array}{c}\text { Mode } \\
\text { II }\end{array}$ \\
\hline SP2 & 25.6 & 41.5 & 8.3 & 59.9 & 101.1 & 0.41 & 20.2 & 0.035 & Mode I \\
\hline SP3 & 26.0 & 42.0 & 8.4 & 60.0 & 105.5 & 0.40 & 22.5 & 0.013 & $\begin{array}{c}\text { Mode } \\
\text { II }\end{array}$ \\
\hline SP4 & 25.1 & 44.0 & 8.8 & 61.1 & 121.2 & 0.36 & 38.7 & 0.027 & $\begin{array}{c}\text { Mode } \\
\text { III }\end{array}$ \\
\hline
\end{tabular}

$\mathrm{P}_{\mathrm{cr}}$ : The beam first crack load, $\mathrm{M}_{\mathrm{tcr}}$ : The accompanied torsional moment, $\mathrm{f}_{\mathrm{c}}$ ': The average 28day concrete cylinder strength, Mode I: Beam failure due to shear force and torsional moment, Mode II: Shear failure at joint panel, Mode III: Shear failure at joint panel followed by beam deterioration due to torsional moment. The modes of failure are discussed and detailed at 4.1

The cracking/failure loads ratio showed differences among the tested specimens which can be related to the corresponding modes of failure. It is clear that the less the ratio of cracking/failure loads, the more the resisting capacity the specimen have. it was observed that the lowest values of cracking to failure loads ratios was recorded for the specimens failed by Mode III of failure (SP4) due to the higher capacity provided by the existence of the joint stirrups and the hooked-ended configuration of the side and secondary steel bars. Specimens failed by Mode I and Mode II of failure showed higher values of cracking/failure loads which can be related to the absence of joint stirrups and the straight-ended configuration of the side and secondary steel.

\subsection{Experimental measurements}

The test specimens were classified according to test parameters into two groups as illustrated in Table 3. The load-deflection behaviour, the torque-twist behaviour and the ductility index results were monitored and discussed for all groups of specimens.

\subsubsection{Load-deflection behaviour}

Load-deflection relationships of all tested specimens are presented in Figure 5. All loaddeflection responses showed approximately the same trend at low loading level. Initially, and up to the initiation of the flexural-shear crack of the beam, a linear elastic behaviour was exhibited. In all specimens, the flexural-shear cracking preceded the development of inclined shear cracking. The flexural-shear crack (as shown in Table 2) resulted in an observed decrease in the instantaneous stiffness of the beams. After the formation of the joint shear cracking, the stiffness generally started to decrease more rapidly and up to failure. 
Table 3. Description of comparative groups.

\begin{tabular}{|c|c|c|c|}
\hline $\begin{array}{l}\text { Main } \\
\text { group }\end{array}$ & $\begin{array}{l}\text { Sub- } \\
\text { group }\end{array}$ & $\begin{array}{l}\text { Compared } \\
\text { Specimens }\end{array}$ & Investigated parameters \\
\hline \multirow{2}{*}{$\begin{array}{l}\text { Group } \\
\text { (I) }\end{array}$} & $\begin{array}{c}\text { Group (I- } \\
\text { a) }\end{array}$ & $\begin{array}{c}\text { SP1 \& } \\
\text { SP3 }\end{array}$ & \multirow{2}{*}{$\begin{array}{l}\text { The steel straight-ended and hooked-ended } \\
\text { configurations of beam was studied in case of } \\
\text { absence of joint stirrups and named group (I-a) } \\
\text { and also was studied in case of existence of joint } \\
\text { stirrups and named group (I-b). }\end{array}$} \\
\hline & $\begin{array}{c}\text { Group (I- } \\
\text { b) }\end{array}$ & $\begin{array}{l}\text { SP2 \& } \\
\text { SP4 }\end{array}$ & \\
\hline \multirow{2}{*}{$\begin{array}{l}\text { Group } \\
\text { (II) }\end{array}$} & $\begin{array}{l}\text { Group } \\
\text { (II-a) }\end{array}$ & $\begin{array}{c}\text { SP1 \& } \\
\text { SP2 }\end{array}$ & \multirow{2}{*}{$\begin{array}{l}\text { The existence of joint stirrups was studied in } \\
\text { case of straight-ended side \& secondary steel } \\
\text { and named group (II-a), in case of hooked-ended } \\
\text { side \& secondary steel and named group (II-b) } \\
\text { and finally was studied in case of e }=400 \mathrm{~mm} \\
\text { and named group (II-c). }\end{array}$} \\
\hline & $\begin{array}{l}\text { Group } \\
\text { (II-b) }\end{array}$ & $\begin{array}{l}\text { SP3 \& } \\
\text { SP4 }\end{array}$ & \\
\hline
\end{tabular}

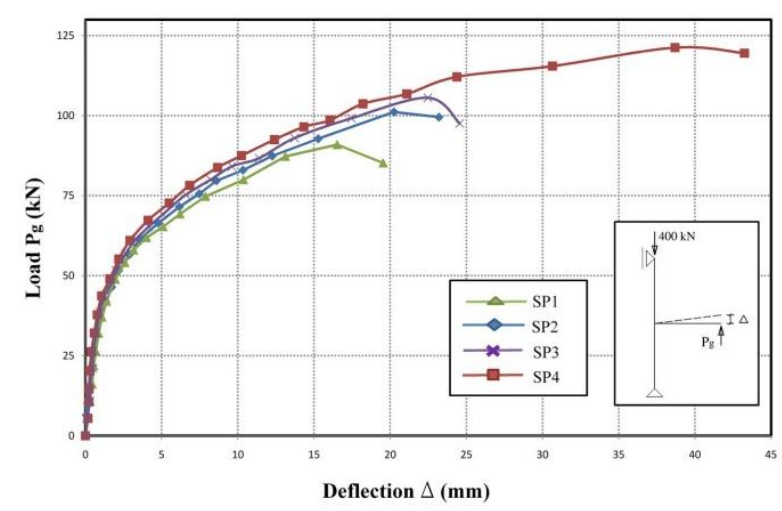

Figure 5. Load-deflection relationship for all tested specimens.

According to the test results of group (I-a), the load capacity of specimen SP3 recorded 16\% higher than that of specimens SP1 while the corresponding beam deflection of specimen SP3 was $36 \%$ more than that of specimens SP1. For group (I-b), the load capacity of specimenSP4 recorded 19\% higher than that of specimen SP2 and the corresponding beam deflection of specimen SP4 was 91\% more than that of specimen SP2. Specimen SP4 experienced higher deflection than exhibited by specimen SP2 due to high loading level which resulted from the different failure mode. Specimen SP4 failed by shear stresses at joint panel while specimen SP2 failed by shear stresses at beam zone at lower loading level. For specimens SP2 and SP1, the instantaneous stiffness degraded more rapidly after the formation of the joint shear cracking. This can be attributed to that the straight-ended side and secondary reinforcing steel crossing the joint was significantly affected by joint cracking. Specimens of group (II) showed approximately similar stiffness until the formation of the joint shear cracking which owing to joint stirrups effect. Specimen SP2 of group (II-a), which included reinforcing stirrups at the joint panel, recorded $11 \%$ higher load capacity than that of specimen SP1 without joint stirrups and beam deflection of SP2 was 23\% more than that of specimen SP1 due to the higher loading level. Specimen SP4 of group (II-b) recorded 15\% higher load capacity than that of specimen SP3 without joint stirrups. The beam deflection of SP4 was $72 \%$ more than that of specimen SP3 due to the different failure mode and the higher capacity of specimen SP3. After the formation of the joint shear cracking, the stiffness degradation of specimens SP1 and SP2 is more than the stiffness degradation of specimens SP3 and specimen SP4 and that may be due to the effect of the hooked-end configuration of the steel crossing the joint shear cracks. 


\subsubsection{Torque-twist behaviour}

Figure 6 shows the torque-twist relationships for all tested specimens. The torque-twist relationships show a similar trend up to the initiation of the flexure-shear crack for the beam, where a linear elastic behaviour was observed. Torsional stiffnesses of the beams showed a slight decrease after the formation of the flexural-shear cracks.

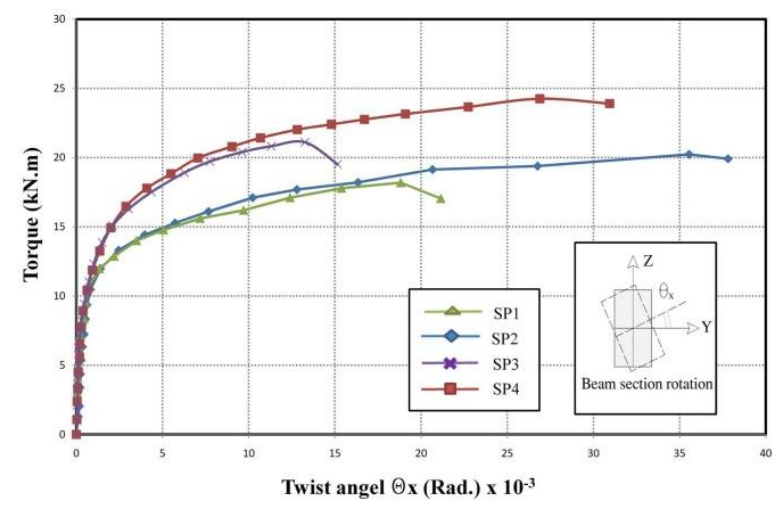

Figure 6. Torque-twist relationship for all tested specimens.

Straight-ended configuration of the side longitudinal steel of group (I-a) resulted in an increase by about $42 \%$ for the beam twist of specimen SP1 more than that of specimen SP3. For group (I-b), this increase became 32\% when compared the manifested beam twist angle of specimen SP2 to that of specimen SP4. Despite the effect of joint shear cracking was not significantly observed in torque-twist relationships of specimens with hooked-ended configuration for side steel, the stiffness of specimens SP1 and SP2 of group (I) started to decrease more rapidly after the joint shear crack propagation that may be due to the effect of joint cracks on the bond of longitudinal side reinforcing bars crossing the joint panel. It is important to mention that the specimens of group (I) showed approximately the same slope (torsional stiffness) until the formation of the joint shear cracking. Longitudinal steel configuration of specimen SP4 led to increase the efficiency of longitudinal side steel and ensured higher torsional capacity, which led to relocate the failure zone from Mode I for specimen SP2 to be Mode III for specimen SP4 due to the higher loading level and the enhanced efficiency of the beam to transmit the internal forces of the beam to the joint panel. Specimens SP1 and SP3 failed at low loading level due to the absence of joint stirrups which exhibited the same mode of failure (Mode II). For specimens of group (II), only the torquetwist relationships of specimens SP1 and SP2 showed an observed decrease of torsional stiffness at the point at which the joint shear cracking was propagated. Absence of joint stirrups caused the tested specimens of group (II) to be failed by Mode II of failure. The existence of joint stirrups for group (II-a) resulted in a higher loading level so that the beam twist of specimen SP2 was $89 \%$ more than that of specimen SP1. Also the existence of the joint stirrups resulted in an increase of the beam twist of specimen SP4 by $103 \%$ more than that of specimen SP3.

\subsubsection{Ductility index}

Ductility index for load-deflection (P-D) curves can be defined as the ratio between the deflections at failure load and yield load. The same procedure can be adopted to calculate the ductility index for Torque-twist $\left(\mathrm{M}_{\mathrm{t}}-\theta\right)$ curves by dividing the twist angel of the beam at ultimate point by the corresponding twist angel at yielding point. The definition of ultimate and yield points vary among the previous researches according to the configuration of tested 
specimens (Jang et al. 2008 and Park 1989). According to Park (1989), the ultimate and yield points was defined as shown in Figure 7.
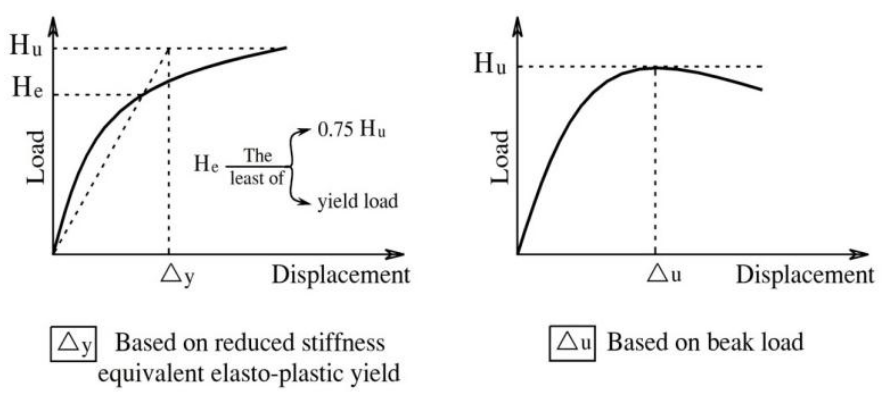

Figure 7. Ultimate and yield points definitions according to Park (1989).

Table 4 summarizes the results of the ductility indices for the tested specimens. The calculation of ductility index was based on load-deflection and torque-twist relationships shown in Figs 6 and 7. It can be noted that specimen SP4 with hooked-ended configuration for both the side and secondary steel reinforcement exhibited the highest P-D ductility index among all specimens. That can be attributed to the higher capacity provided by the effect of the hooked-ended configuration of side steel and the existence of the joint stirrups. On the other hand, it was observed that specimen SP2 showed the highest value of $\mathrm{M}_{t}-\theta$ ductility index due to the large recorded twist angel. That can be attributed to the effect of the straightended side reinforcing steel slippage triggered by the cracking of joint panel.

Table 4. ductility index results.

\begin{tabular}{|c|c|c|c|c|}
\hline Specimen & SP1 & SP2 & SP3 & SP4 \\
\hline $\begin{array}{c}\text { P-D } \\
\text { ductility index }\end{array}$ & 2.1 & 2.04 & 2.08 & 2.43 \\
\hline $\begin{array}{c}\mathrm{M}_{\mathrm{t}}-\theta \\
\text { ductility index }\end{array}$ & 4.82 & 5.22 & 3.77 & 4.07 \\
\hline
\end{tabular}

The effect of steel configuration was noticed for specimen SP4 with hooked-ended type of side longitudinal steel which showed an increase of P-D ductility index by $19 \%$ higher than that of specimen SP2 with straight-ended type of side longitudinal steel. Although the specimen of straight-ended configuration of side longitudinal steel, SP1, recorded approximately the same P-D ductility index as that of specimen SP3 of hooked-ended configuration which owing to the low loading level and the similarity of failure mode (Mode II) due to the absence of the joint stirrups. It is clearly observed that the $M_{t}-\theta$ ductility index increased for specimens SP2 and SP1 with straight-ended configuration of side steel by approximately the same ratio of $28 \%$ than that of specimens of hooked-ended configuration, SP4 and SP3, respectively. That can be attributed to the large rotational angel recorded for the specimens of the straight-ended configurations. The effect of joint stirrups was observed for SP2 where the joint stirrups were provided which showed approximately the same P-D ductility index of specimen SP1 without joint stirrups due to the effect of straight-ended configuration of steel. However, specimen SP4 with joint stirrups experienced an increase of P-D ductility index and recording 17\% more than that of specimen SP3 without joint stirrups. Due to the higher twisting angel experienced by the straight-ended specimens, The $M_{t}-\theta$ ductility index of SP1 and SP2 showed approximately the same difference of $28 \%$ more than that of SP3 and SP4, respectively. The $M_{t}-\theta$ ductility index increased for specimens SP2 and 
SP4 with joint stirrups by approximately the same value of $8 \%$ than those of specimens without joint stirrups SP1 and SP3, respectively, due to the higher loading level.

\section{Conclusions}

Based on the experimental findings, the following observations were found.

1- Straight-ended side steel configurations of the beam provided lower response of the joint and led the specimen to fail at beam zone due to shear stresses. Thus, hooked-ended side steel configurations enabled the specimens adopting this configuration to outperform their response and were more efficient to transfer the straining action from the beam to the joint panel.

2- Hooked-ended configuration of the beam side steel into the joint panel including stirrups contributed to relocate the shear failure from beam zone at straight-ended configuration of specimen SP2 (Mode I) to the joint panel at the extended hooked-ended configuration of specimen SP4 (Mode III).

3- In the case of the absence of the joint stirrups, the hooked-ended configuration of the side steel contributed to increase the ultimate capacity of specimen SP3 than that of specimen SP1. That can be attributed to the effect of hooked-ended side steel bars of the beam crossing the joint panel that worked as internal branches of joint stirrups.

was performed in the Reinforced Concrete and Heavy Structures Laboratory of Faculty of Engineering, Tanta University, Tanta, Egypt.

\section{References}

1- ACI Committee 318, "Recommendations for design of beam-column connections in monolithic reinforced concrete structures (ACI 352R-2)", become effective June 18, 2002.

2- ACI Committee 318, "Building Code Requirements for Structural Concrete (ACI 31802) and Commentary (ACI 318R-02)," American Concrete Institute, Farmington Hills, 2002, $443 \mathrm{pp}$.

3- ACI Committee 318, "Building Code Requirements for Reinforced Concrete (ACI 31883)", Detroit, MI, 1971.

4- Architectural Institute of Japan, Design Guideline for Earthquake Resistant Reinforced Concrete Building Based on Ultimate Strength Concept, 1988.

5- Architectural Institute of Japan: AIJ Standard for Structural Calculation of Reinforced Concrete Structures, Tokyo, 1999.

6- Egyptian Code for Design and Construction of Reinforced Concrete Structures, (ECP 203-2007) 2007.

7- IS 13920, Ductile detailing of reinforced concrete structures subjected to seismic forces (reaffirmed 2003), New Delhi: Bureau of Indian Standards, India, 1993.

8- J. S. Kaung and H. F. Wong, "Effectiveness of Horizontal Stirrups in Joint Core for Exterior Beam-Column Joints with Non-seismic Design", Procedia Engineering, Vol. 14 (2011) 3301-3307.

9- J. Zhou, M. Hirosawa, T. Konda and Y. Shimizu, "Effect of the torsional moment on the shear strength of reinforced concrete columns due to eccentric jointing of beam to column", the 12th world conference of earthquake engineering, (2000) Paper No. 859.

10- J.D. Zhou, M. Hirosawa and Y. Shimizu, "Study on effect of torsional moment to shear strength of RC columns (Discussion a RC school building damaged during Kagoshima- 
ken Hokuseibu earthquake)", the 10th Earthquake Engineering Symposium (1998), pp297-302.

11- R. Kiran and G. Genesio, "A case study on pre 1970s constructed concrete exterior beam-column joints", Case Studies in Structural Engineering, Vol.1 (2014) 20-25.

12- R. P. Dhakal, T. C. Pan, P. Irawan, K.C. Tsai, K.C. Lin and C.H. Chen, "Experimental study on the dynamic response of gravity-designed reinforced concrete connections", Engineering Structures, Vol. 27 (2005) 75-87.

13- R. Park, "Evaluation of ductility of structures and structural assemblages from laboratory testing", Bulletin of the New Zealand national society for earthquake engineering, Vol. 22 (1989) No.3.

14- S. M. Kularni and Y. D. Patil, "A Novel Reinforcement Pattern for Exterior Reinforced Concrete Beam-Column Joint”, Procedia Engineering, Vol. 51 (2013) 184 - 193.

15- W. A. Thanoon, "Influence of torsion on the inelastic response of three-dimensional RC frames", Finite Elements in Analysis and Design, Vol. 40 (2004) 611-628.

16- Y. Goto and O. Joh, "Shear resistance of RC interior eccentric beam-column joints", the 13th world conference of earthquake engineering, (2004) Paper No.649.

17- Y. Jang, H. G. Park, S. S. Kim, J. H. Kim, and Y. G. Kim, "The Ductility of HighStrength Concrete Beams", International Journal of Concrete Structures and Materials, Vol.2 (2008) 115-122. 